Artikel Penelitian

\title{
Pengobatan Berpotensi Tidak Tepat Berdasarkan Kriteria Beers 2015 Pada Pasien Geriatri di RSUD Prof. Dr. Margono Soekarjo
}

\author{
Potentially Inappropriate Medications (PIMs) based on Beers Criteria 2015 In \\ Geriatri Prof. Dr. Margono Soekarjo Hospital
}

\author{
Annisaa Ayu Nabilla, Esti Dyah Utami*, Ika Mustikaningtias \\ Jurusan Farmasi, Fakultas Ilmu-ilmu Kesehatan, Universitas Jenderal Soedirman, Purwokerto \\ *E-mail: estinesia@gmail.com
}

\begin{abstract}
Abstrak
Geriatri berpotensi mengalami pengobatan berpotensi tidak tepat atau potentially inappropriate medications (PIMs). Kriteria Beers 2015 merupakan kriteria untuk mengidentifikasi PIMs. Pengambilan sampel secara retrospektif dengan pengambilan sampel acak sederhana. Hasil penelitian menunjukkan paling banyak berusia $75-90$ tahun, jenis kelamin laki-laki, lama rawat $<7$ hari dengan polifarmasi $\geq 5$ macam obat. Dari 97 pasien, sebanyak 93 mengalami kejadian PIMs dengan 261 kejadian PIMs. Obat yang dihindari adalah omeprazol $(31,57 \%)$. Obat yang masih bisa digunakan dengan hati-hati adalah furosemid $(45,68 \%)$. Obat yang membutuhkan penyesuaian dosis adalah ranitidin $(11,11 \%)$. Interaksi obat yang paling banyak adalah ketorolak dengan metilprednisolon $(42,85 \%)$ dengan kondisi gagal jantung dan ginjal $(28,57 \%)$.
\end{abstract}

Kata kunci: geriatri, kejadian PIM, Beers Criteria 2015

\begin{abstract}
Geriatrics has the potential to experience Potentially Inappropriate Medications (PIMs). Beers Criteria 2015 is a criterion for identifying PIMs. Sampling retrospectively with simple random sampling. The results showed most aged 75-90 years, male sex, length of stay $<7$ days with polypharmacy $\geq 5$ kinds of drugs. Of 97 patients, 93 experienced PIMs with 261 PIMs. The drug that was avoided was omeprazole (31.57\%). The drug that can still be used cautiously is furosemide $(45.68 \%)$. The drug that requires dose adjustment is ranitidine $(11.11 \%)$. The most drug interaction is ketorolac with methylprednisolone $(42.85 \%)$ with heart and kidney failure $(28.57 \%)$.
\end{abstract}

Keywords: geriatric, Beers Criteria 2015, PIM events

\section{PENDAHULUAN}

Geriatri adalah seseorang yang telah mencapai usia lebih dari 60 tahun (Kemenkes RI, 2014). Populasi lansia diprediksi terus mengalami peningkatan. Indonesia sudah memasuki era penduduk menua (ageing population). Pada tahun 2015, angka kesakitan pada geriatri sebesar 28,26\% (Kemenkes RI, 2017). Pada geriatri terjadi penurunan pada farmakokinetika dan farmakodinamika, sehingga perlu adanya penyesuaian dalam 
penggunaan obat-obatan. Resiko untuk mengalami efek samping dan interaksi obat yang merugikan menjadi semakin tinggi (Setyowati et al., 2011). Salah satu kriteria eksplisit yang dapat digunakan untuk mengidentifikasi kejadian PIMs pada pasien geriatri yaitu Beers Criteria. Daftar Beers Criteria dapat mengukur ketidaksesuaian penggunaan obat yang sebaiknya dihindari maupun yang dapat digunakan dengan perhatian khusus. Daftar ini merupakan daftar yang paling mudah, murah, sederhana, data yang diperoleh bersifat reprodusibel, serta memiliki bukti yang kuat dan jelas (Rumore dan Vaidean, 2012). Oleh karena itu, penggunaan obat pada pasien geriatri memerlukan pertimbangan untuk menghindari penggunaan obat yang berpotensi tidak tepat. Menghindari resep obat-obatan yang berpotensi tidak tepat (PIMs) untuk pasien dapat berkontribusi pada perawatan kesehatan yang lebih baik. Hasil penelitian ini diharapkan dapat digunakan sebagai referensi dalam evaluasi pelayanan rumah sakit sehingga keamanan penggunaan obat akan meningkat dan menurunkan resiko morbiditas dan mortalitas pada pasien geriatri di bangsal penyakit dalam RSUD Prof. Dr. Margono Soekarjo.

\section{DESAIN PENELITIAN}

Penelitian ini merupakan penelitian non-eksperimental dengan pengambilan sampel dilakukan secara retrospektif dengan metode pengambilan sample acak sederhana. Penelitian dilakukan selama delapan bulan dengan mengambil data rekam medik pasien geriatri bangsal penyakit dalam dalam periode Januari - Desember 2018 selama 1 bulan. Jumlah pasien geriatri rawat inap di RSUD Prof. Dr. Margono Soekarjo pada tahun 2018 di bangsal penyakit dalam ruang mawar adalah 856 pasien. Sampel yang diambil yaitu 115 data rekam medik dan sejumlah 97 data yang telah memenuhi kriteria inklusi. Data yang diambil dari rekam medik yaitu nama pasien, usia, jenis kelamin, diagnosis, lama rawat inap, jenis obat, dosis obat, frekuensi obat, dan jumlah obat yang diresepkan. Data penunjang lain yang digunakan adalah data laboratorium dengan mengambil data klirens kreatinin dari pasien.

Karakteristik pasien yaitu data pasien geriatri meliputi usia, jenis kelamin, diagnosis, dan lama rawat inap (tanggal masuk dan keluar rumah sakit). Karakteristik obat dalam penelitian ini adalah jenis obat, dosis obat, frekuensi obat, dan jumlah obat yang diresepkan selama rawat inap. Usia pasien geriatri dalam penelitian ini dibagi menjadi 3 interval kelas yaitu 60-74 tahun, 75-90 tahun, dan $>90$ tahun (WHO, 2011). Lama rawat inap pasien dibagi menjadi 2 interval kelas yaitu $<7$ hari dan $\geq 7$ hari. Jumlah obat yang diterima pasien dibagi menjadi 2 interval kelas yaitu $<5$ dan $\geq 5$ macam. Pemberian $2-4$ obat disebut polifarmasi minor sedangkan $\geq 5$ obat disebut polifarmasi mayor (Dasopang et al., 2015). Jenis PIMs berdasarkan Beers Criteria 2015 ini dibagi menjadi 5 kategori yaitu obat yang secara umum harus dihindari, kejadian PIMs yang dikarenakan adanya interaksi antara penyakit dengan obat, obat yang masih dapat digunakan namun dengan perhatian khusus atau hati-hati, kejadian PIMs karena adanya interaksi antar obat, dan obat yang harus dihindari atau diturunkan dosisnya (AGS, 2015).

\section{Analisis data}

Analisis data dilakukan dari lembar pengumpul data yaitu data profil pasien dibuat tabulasi meliputi karakteristik pasien, karakteristik obat, dan kejadian PIMs. Analisis data dilakukan dengan metode deskriptif. Persentase karakteristik pasien dan obat dihitung dengan cara jumlah per kategori yaitu usia, jenis kelamin, diagnosis, lama rawat inap dan jumlah obat dari jumlah keseluruhan pasien. 


\section{HASIL DAN PEMBAHASAN}

\section{Karakteristik pasien}

Usia pasien geriatri di RSUD Prof. Dr. Margono Soekarjo Purwokerto yang paling banyak adalah pada kelompok usia 60-74 tahun (elderly) sebesar 81 pasien $(83,5 \%)$ dan yang paling sedikit yaitu kelompok usia $\geq 90$ tahun sebanyak 1 pasien $(1,03 \%)$.

Tabel 1. Gambaran karakteristik pasien geriatri

\begin{tabular}{|l|l|l|l|}
\hline No & Kategori & Jumlah pasien & $\%$ \\
\hline 1 & Usia (WHO, 2011) & & \\
\hline & $60-74$ tahun & 81 & 83,5 \\
\hline & $75-90$ tahun & 15 & 15,5 \\
\hline & $\geq 90$ tahun & 1 & 1 \\
\hline & Total & 97 & 100 \\
\hline 2 & Jenis kelamin & & \\
\hline & Laki-laki & 58 & 59,8 \\
\hline & Perempuan & 39 & 40,2 \\
\hline & Total & 97 & 100 \\
\hline 3 & Lama rawat inap & & \\
\hline & $<7$ hari & 51 & 52,6 \\
\hline & $\geq 7$ hari & 46 & 47,4 \\
\hline & Total & 97 & 100 \\
\hline 4 & Jumlah obat yang diresepkan & & \\
\hline & $<5$ macam & 12 & 12,4 \\
\hline & $\geq 5$ macam & 85 & 87,6 \\
\hline & Total & 97 & 100 \\
\hline
\end{tabular}

Karakteristik pasien geriatri berdasarkan jenis kelamin menunjukkan jumlah pasien lakilaki $59,79 \%$ lebih banyak daripada pasien perempuan yaitu $40,2 \%$. Pada penelitian ini, didapatkan hasil yaitu pasien geriatri dengan durasi rawat inap selama $<7$ hari sebanyak 51 pasien $(52,57 \%)$ lebih banyak dibandingkan dengan pasien yang dirawat $\geq 7$ hari yaitu sebanyak 46 pasien $(47,42 \%$ ). Jumlah pasien antara lama rawat $<7$ hari dan $\geq 7$ hari tidak berbeda signifikan. Hal ini berbeda dengan penelitian Puspitasari (2013) menunjukan bahwa lamanya pasien dirawat inap tidak menunjukkan semakin banyaknya penyakit yang diderita semakin tingginya obat yang diberikan yang akan berpengaruh pada PIMs. Hasil penelitian ini menunjukkan pasien yang diresepkan $\geq 5$ macam obat (polifarmasi mayor) lebih banyak dibandingkan dengan pasien yang diresepkan $<5$ macam obat (polifarmasi minor) yaitu pasien dengan polifarmasi mayor sebanyak 85 pasien $(87,62 \%)$ dan 12 pasien $(12,37 \%)$ untuk polifarmasi minor. 


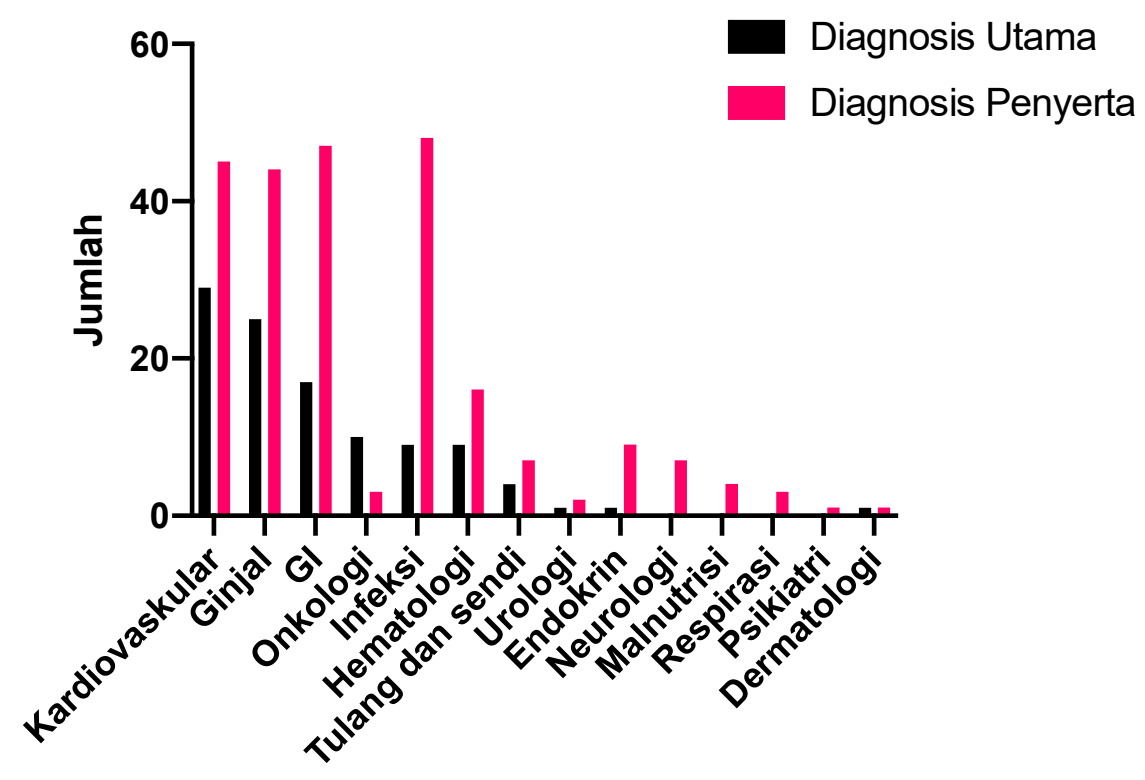

Gambar 1. Diagnosis penyakit pada subjek geriatri

Gambar 1 menunjukkan diagnosis utama dan penyerta yang terjadi pada pasien. Penyakit kardiovaskular menjadi penyakit yang banyak diderita pasien geriatri sebagai diagnosa utama (29 kejadian atau 27,35\%). Peningkatan prevalensi penyakit kardiovaskular pada geriatri disebabkan oleh perubahan struktur anatomik, fungsional, dan histopatologik sistem kardiovaskuler serta terjadinya peningkatan prevalensi hipertensi (Dai et al., 2015). Diagnosis penyerta pada penelitian ini paling banyak adalah penyakit infeksi sebesar 48 kejadian $(20,25 \%)$ dengan mayoritas penyakit infeksi saluran kemih yaitu 15 kejadian.

\section{Kejadian Potentially Inappropriate Medications (PIMs)}

Beers Criteria merupakan suatu standar penggunaan obat pada pasien geriatri yang berisi obat-obat yang tidak boleh digunakan atau dihindarkan pada geriatri. Pada penelitian ini, hampir semua pasien geriatri jumlah pasien geriatri sebanyak 93 pasien $(95,87 \%)$ di ruangan mawar bangsal penyakit dalam RSUD Prof. Dr. Margono Soekarjo Purwokerto mengalami paling tidak satu atau lebih kejadian PIMs, sedangkan pasien yang tidak mengalami PIMs sebanyak 4 pasien $(4,12 \%)$. Dari 93 pasien yang mengalami PIMs, teridentifikasi total 261 kejadian PIMs.

Tabel 2 menggambarkan bahwa obat yang paling banyak digunakan yang sebaiknya dihindari oleh pasien geriatri. Obat-obat tersebut yaitu golongan pompa proton inhibitor (PPI) seperti omeprazol dan lansoprazol. Penggunaan PPI dapat meningkatkan resiko infeksi Clostridium difficile dan fraktur tulang pada pasien geriatri (AGS, 2015). Penggunaan PPI harus dihindari pada pasien geriatri, terutama penggunaan untuk terapi jangka panjang (lebih dari 8 minggu). 
Tabel 2. Penggunaan obat yang masuk dalam kategori harus dihindari

\begin{tabular}{|c|c|c|}
\hline No & Golongan obat dan obat & $\begin{array}{c}\text { Jumlah } \\
\text { (n) }\end{array}$ \\
\hline \multirow[t]{3}{*}{1} & Proton pump inhibitor (PPI) & \\
\hline & Omeprazol & 30 \\
\hline & Lansoprazol & 12 \\
\hline \multirow[t]{3}{*}{2} & Antispasmodik & \\
\hline & Klidinium-klordiazepoksid & 9 \\
\hline & Hiosin/skopolamin butilbromida & 7 \\
\hline \multirow[t]{5}{*}{3} & NSAID & \\
\hline & Ketorolak & 17 \\
\hline & Na diklofenak & 2 \\
\hline & Ibuprofen & 2 \\
\hline & Meloksikam & 2 \\
\hline \multirow[t]{2}{*}{4} & Gastrointestinal & \\
\hline & Metoklopramid & 4 \\
\hline \multirow[t]{2}{*}{5} & Barbiturat & \\
\hline & Alprazolam & 5 \\
\hline \multirow[t]{3}{*}{6} & Kardiovaskular & \\
\hline & Amiodaron & 3 \\
\hline & Total & 95 \\
\hline
\end{tabular}

Tabel 3 menggambarkan bahwa beberapa penyakit dapat berinteraksi dengan obat. Pada penelitian ini, interaksi yang banyak terjadi pada pasien dengan gagal jantung dan gagal ginjal menerima obat NSAID yaitu ketorolak sebanyak 4 kejadian $(28,57 \%)$ dan natrium diklofenak sebanyak 1 kejadian (7,14\%). Menurut Beers Criteria 2015, NSAID harus dihindari pada pasien geriatri dengan riwayat penyakit gagal jantung karena berpotensi memperburuk kondisi gagal jantung. Penggunaan NSAID pada penyakit gagal jantung dapat berpotensi memicu adanya retensi cairan dan eksaserbasi gagal jantung. Penggunaan NSAID pada pasien gagal ginjal dapat meningkatkan risiko gagal ginjal akut dan selanjutnya dapat menurunkan fungsi ginjal.

Tabel 3. Penggunaan obat yang berinteraksi dengan penyakit

\begin{tabular}{lllcc}
\hline No & Penyakit & Obat & Jumlah & $\mathbf{( \% )}$ \\
\hline 1. & Gagal jantung & Ketorolak & 4 & 28.6 \\
& & Na diklofenak & 1 & 7,1 \\
2. & Gangguan ginjal & Ketorolak & 4 & 28,6 \\
& & Na diklofenak & 1 & 7,1 \\
3. & Infeksi saluran kemih & Hiosin & 4 & 28,6 \\
\hline \multicolumn{2}{l}{ Total } & & $\mathbf{1 4}$ & $\mathbf{1 0 0}$ \\
\hline
\end{tabular}

Tabel 4 menggambarkan penggunaan obat yang masih bisa digunakan, tetapi harus dengan hati-hati oleh pasien geriatri. Pada penelitian ini obat yang sering diberikan adalah obat golongan diuretik yaitu furosemid sejumlah 53 kejadian $(45,68 \%)$ dan obat golongan vasodilator yaitu isosorbid dinitrat atau ISDN sejumlah 17 kejadian $(14,62 \%)$. Berdasarkan Beers Criteria 2015, penggunaan obat golongan diuretik (furosemid) dapat digunakan dengan perhatian khusus yaitu dengan adanya monitoring kadar natrium perubahan dosis karena dapat menyebabkan eksaserbasi atau syndrome of inappropriate antidiuretic hormone secretion (SIADH) atau hiponatremia. 
Tabel 4 Penggunaan obat yang dapat digunakan dengan hati-hati

\begin{tabular}{|c|c|c|c|}
\hline No. & Nama Obat & Jumlah & $(\%)$ \\
\hline \multirow[t]{3}{*}{1.} & Diuretik & & \\
\hline & - Furosemid & 53 & 45,7 \\
\hline & - Spironolakton & 12 & 10,3 \\
\hline \multirow[t]{8}{*}{2.} & Vasodilator & & \\
\hline & - Amlodipin & 13 & 11,2 \\
\hline & - Ramipril & 6 & 5,1 \\
\hline & - Valsartan & 6 & 5,1 \\
\hline & - Candesartan & 2 & 1,7 \\
\hline & - Bisoprolol & 5 & 4,3 \\
\hline & - ISDN & 17 & 14,7 \\
\hline & - Kaptopril & 1 & 0,8 \\
\hline \multirow[t]{3}{*}{3.} & SSRI & & \\
\hline & - Fluoksetin & 1 & 0,8 \\
\hline & Total & 116 & 100 \\
\hline
\end{tabular}

Obat yang digunakan pasien geriatri dapat berinteraksi dengan obat lain. Pada penelitian ini, potensi interaksi yang terjadi yaitu antara golongan kortikosteroid (metilprednisolon, dekstametason) dengan NSAID (ketorolak, natrium diklofenak, meloksikam) dengan jumlah interaksi sebanyak 7 kejadian. Penggunaan antara obat golongan kortikosteroid oral maupun parenteral dengan obat golongan NSAID seharusnya dihindari atau jika tidak memungkinkan harus diberikan proteksi gastrointestinal karena terapi ini dikaitkan dengan adanya peningkatan resiko gastrointestinal yang merugikan termasuk gastritis, ulkus lambung, perdarahan serta dispepsia (AGS, 2015; Liu et al., 2013).

Beberapa penggunaan obat ranitidin termasuk dalam kategori kejadian PIMs berdasarkan Beers Criteria 2015 yang seharusnya dihindari atau diturunkan dosisnya. Pada hasil penelitian ini, penggunaan ranitidin merupakan golongan obat yang paling banyak diresepkan dalam terapi sistem gastrointestinal dengan nilai klirens kreatinin $(\mathrm{CrCl})<50 \mathrm{ml} / \mathrm{min}$ sebanyak 29 kejadian (11,11\%). Pada penelitian ini, pasien menerima ranitidin setiap ampulnya mengandung dosis $50 \mathrm{mg} / \mathrm{ml}$ dengan cara injeksi atau $150 \mathrm{mg}$ tablet secara per oral dengan frekuensi 2 kali sehari. Hal ini tidak sesuai dengan data Food Drug Administration (2009) yang menunjukkan bahwa dosis ranitidin yang dianjurkan pada pasien yang menggunakan obat ranitidin dengan klirens kreatinin $(\mathrm{CrCl})<50 \mathrm{ml} /$ menit yaitu $150 \mathrm{mg}$ setiap 24 jam.

\section{KESIMPULAN}

Kejadian PIMs berdasarkan Beers Criteria 2015 pada pasien geriatri di ruang mawar bangsal penyakit dalam RSUD Prof. Dr. Margono Soekarjo pada tahun 2018 masih sangat tinggi terjadi pada 93 pasien $(95,87 \%)$. Jenis PIMs yang teridentifikasi menurut Beers Criteria 2015 adalah obat yang secara umum harus dihindari (36,39\%), kejadian PIMs yang dikarenakan adanya interaksi antara penyakit dengan obat $(5,36 \%)$, obat yang masih dapat digunakan tetapi dengan perhatian khusus atau hati-hati $(44,44 \%)$, kejadian PIMs karena adanya interaksi antar obat $(2,68 \%)$, dan obat yang harus dihindari atau diturunkan dosisnya $(11,11 \%)$.

\section{REFERENSI}

American Geriatrics Society (AGS), 2015, American Geriatrics Society 2015 Updated Beers Criteria for Potentially Inappropriate Medication Use in Older Adults, J Am Geriatr Soc, 63(11): 2227-2246. doi: $\underline{10.1111 / \text { jgs. } 13702}$ 
Dai X, Hummel SL, Salazar JB, Taffet GE, Zieman S, Schwartz JB. 2015, Cardiovascular physiology in the older adults. J Geriatr Cardiol. 12(3):196-201. doi: 10.11909/j.issn.1671-5411.2015.03.015

Dasopang, E. S., Harahap, U., dan Lindarto, D., 2015, Polifarmasi dan Interaksi Obat Pasien Usia Lanjut Rawat Jalan dengan Penyakit Metabolik, Jurnal Farmasi Klinik Indonesia, 2(4): 235-41, doi: $\underline{10.15416 / 1 j \mathrm{jcp} .2015 .4 .4 .235}$

Food and Drug Administration (FDA), 2009, Food Safety, USA

Imaligy, E. U., 2014, Gagal Jantung Pada Geriatri, CDK-212, 41(1): 19-24

Kemenkes RI, 2014, Peraturan Menteri Kesehatan Republik Indonesia Nomor 79 Tahun 2014 Tentang Penyelenggaraan Pelayanan Geriatri di Rumah Sakit, Depkes RI, Jakarta.

Kemenkes RI, 2017, Analisis Lansia di Indonesia, Kementerian Kesehatan Republik Indonesia, Jakarta.

Kemenkes RI, 2018, Riset Kesehatan Dasar 2018, Depkes RI, Jakarta.

Liu D, Ahmet A, Ward L, Krishnamoorthy P, Mandelcorn ED, Leigh R, et al., 2013, A practical guide to the monitoring and management of the complications of systemic corticosteroid therapy, Allergy Asthma Clin Immunol. 15;9(1):30. doi: 10.1186/1710-1492-9-30

Puspitasari, Rara Merinda, 2013, Uji Efektivitas Screening Tool For Older Peoples' Prescription terhadap pengobatan yang berpotensi tidak tepat pada pasien geriatri di RSUD Kota Depok, Depok: Universitas Indonesia.

Rumore, M.M. dan Vaidean, G., 2012, Development of A Risk Assessment Tool For Falls Prevention In Hospital In Patients Based on The Medication Appropriateness Index (MAI) and Modified Beer's Criteria, Innovations in Pharmacy, 3(1): 1-12. doi: 10.24926/iip.v3i1.256

Setyowati, D.R., Sudarso, Utaminingrum W., 2011, Evaluasi Pola Peresepan Berdasarkan Beers Criteria Pada Pasien Geriatri Rawat Jalan Pada Poli Penyakit Dalam di RSUD Prof. Dr. Margono Soekarjo Purwokerto Periode Agustus 2010-Maret 2011, Pharmacy: Jurnal Farmasi Indonesia, 8(3): 24-28.

World Health Organization, 2011, WHO Global Health and Aging, Geneva.

(C) The Author(s) 2019 